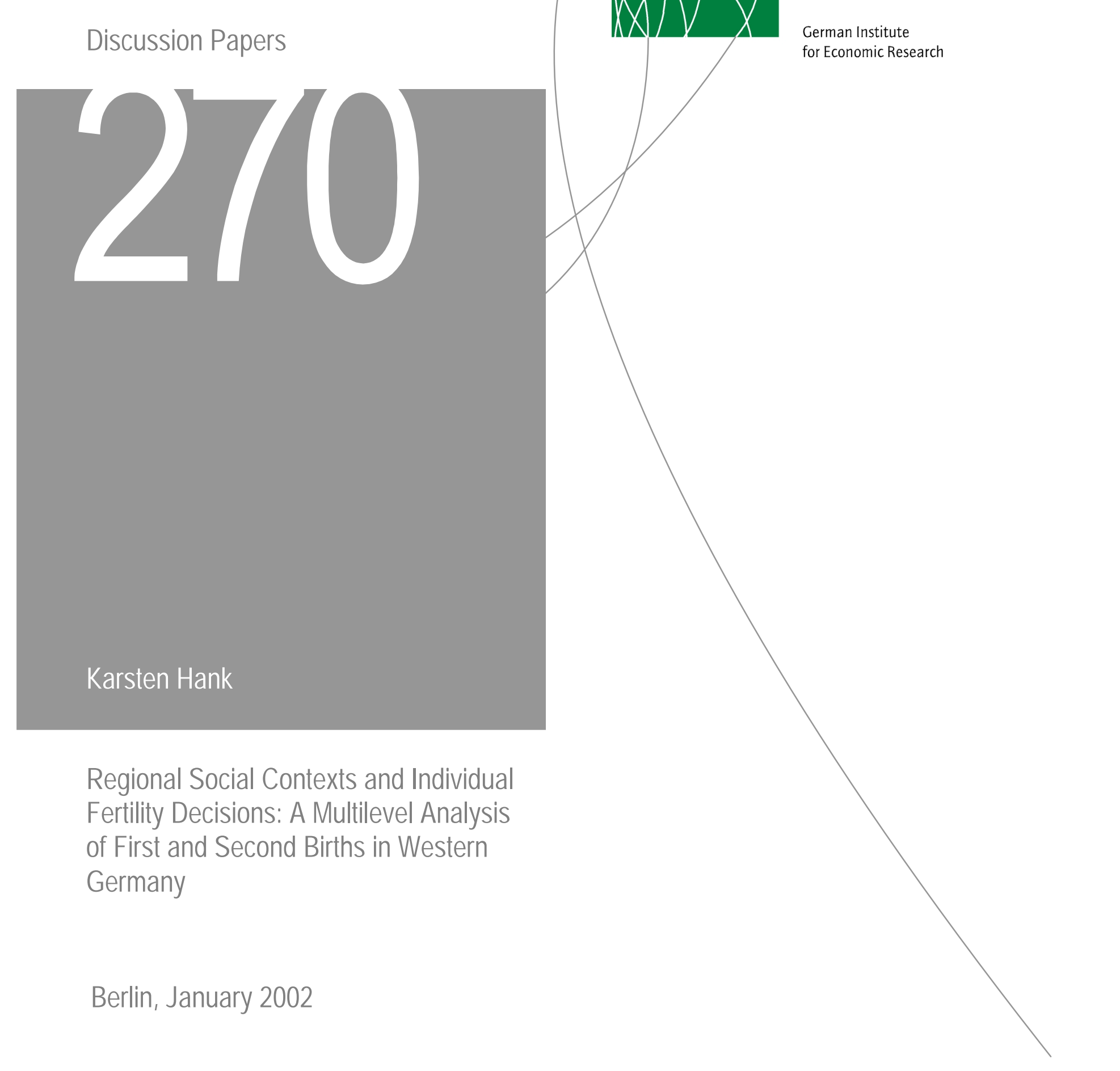


Opinions expressed in this paper are those of the author and do not necessarily reflect views of the Institute.

\section{DIW Berlin}

German Institute

for Economic Research

Königin-Luise-Str. 5

14195 Berlin

Phone (030) $89789-0$

Fax (030) 897 89-200

www.diw.de

ISSN 0702-2345

ISBN 3-345-10015-3 


\title{
Regional Social Contexts and Individual Fertility Decisions: A Multilevel Analysis of First and Second Births in Western Germany
}

\author{
Karsten Hank ${ }^{\star}$
}

January 2002

\begin{abstract}
This paper investigates whether and how regional social contexts influence fertility decisions of women living in western Germany during the 1980s and 1990s. It is argued that regional opportunity structures as well as local patterns of social interaction and culture may translate into parameters that directly affect individual behaviour. Data from the German Socio-Economic Panel (GSOEP) are linked with a set of regional indicators to estimate multilevel discrete-time logit models for the transition to the first and second child. The empirical analysis provides no evidence that fertility differentials observed at the regional level are due to autonomous contextual effects. It is rather suggested that most of the observed regional variation results from differences in the spatial distribution of individual characteristics.
\end{abstract}

Keywords: multilevel analysis, fertility; Germany

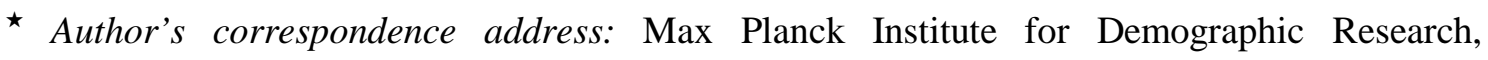
Doberaner Str. 114, 18057 Rostock, Germany. Telephone: +49-381-2081-163. Fax: +49-3812081-463. Email: hank@demogr.mpg.de.

Parts of this paper have been written during a research visit at the DIW Berlin. The kind support of the GSOEP-Team is highly appreciated. I am greatly indebted to Johannes Huinink and Hans-Peter Kohler for many helpful comments and suggestions. I would also like to thank Francesco C. Billari for his advice concerning the statistical model applied here, and Øystein Kravdal for comments on an earlier version of this paper. Last not least, I am grateful to the participants of several workshops and conferences for lively discussions.

The views expressed in this paper are the author's views and do not necessarily reflect those of the Max Planck Institute for Demographic Research. 


\section{Introduction}

Distinct regional diversity in reproductive behaviour could be observed before, during, and after the historical fertility transition in all European countries (see Coale and Watkins 1986 for an overview). Even after the second demographic transition in western countries (Lesthaeghe 1995), substantial regional variation in fertility levels has continued to exist within contemporary European low-fertility societies (e.g., Höpflinger 1983; Kutzenberger and Fürst 1983; Gonzalvez 1989; Brunetta and Rotondi 1991; Noin and Chauviré 1991). In post-unification Germany, however, researchers' attention has been attracted mainly by the rapid fertility decline in eastern Germany and by the question of whether fertility levels in East and West will converge over time (e.g., Conrad et al. 1996). This has often resulted in neglect of different reproductive patterns across regions, which reach much further back in time than those currently observed between the 'old' and the 'new' Länder of the Federal Republic (see Kopp 2000 for an exception).

In a recent review of regional fertility differences in western Germany, Hank (2001a) finds district-level total fertility rates ranging from about 0.9 to 1.9. The geographical pattern of fertility has remained basically unchanged by the general fertility decline of the late 1960s and early 1970s: high-fertility areas are primarily located in the northwestern and southern parts of the country, while extremely low fertility levels are frequently found in university towns. Consistent with results of earlier analyses, population density, family migration, and the occupational structure are found to be closely associated with regional total fertility rates in the 1990s. Little is known, 
though, about the mechanisms that link such local structural parameters to individual childbearing decisions.

Theoretically as well as empirically, the multilevel approach provides an appropriate tool to bridge the micro-macro gap (e.g., Huber 1991; DiPrete and Forristal 1994; Courgeau and Baccaini 1998). However, despite a growing literature that deals with neighbourhood effects on children's life chances and a variety of family-related events in the US (see Burton and Jarrett 2000; Ginther et al. 2000; Jencks and Mayer 1990 for a critical overview of this literature), contextual analyses of reproductive behaviour have so far mainly focussed on developing countries (e.g., Entwisle et al. 1989; Hirschman and Guest 1990; Axinn and Yabiku 2001). In the present study, a multilevel perspective is taken to investigate whether and how regional social contexts influence first and second birth probabilities of women living in western Germany during the period 1984 to 1995 . For the empirical analysis, individual-level data from the German Socio-Economic Panel (GSOEP) are linked with a rich set of regional indicators provided by the Federal Office for Building and Regional Planning (BBR).

The paper is organised as follows: $\underline{\text { Section } 2}$ discusses how regional contexts may operate on individual fertility behaviour. The data, variables, and statistical methods used in this study are described in Section 3. Multilevel discrete-time logit models for the transition to the first and the second child are then estimated in Section 4. Conclusions and perspectives for future research are presented in Section 5. 


\section{How Contexts Operate on Individual Behaviour}

\subsection{Challenges to CONTEXTUAL ANALYSIS}

The implementation of contextual variables in empirical investigations of individual decision-making has often been questioned on general methodological grounds (e.g., Hauser 1974; see Ginther et al. 2000 for a recent review). One of the main arguments in this discussion is the assertion that statistically significant effects of aggregate-level characteristics are merely the result of an underspecification at the individual level. To avoid this 'contextual fallacy', Hauser (1974, p.374) demands thorough consideration of particularly two issues, namely, the meaning of the contextual effect, and explicit selection on the dependent variable.

Many studies do indeed not sufficiently lay out the social mechanisms that shall be responsible for the transfer between contextual properties and individual behaviour. Erbring and Young (1979, pp.400-402) describe such unsatisfying formulations and interpretations of contextual mechanisms as 'social telepathy' or 'common fate'. There are, however, a number of interchange hypotheses that lend themselves to explain how contextual properties might translate into parameters that directly affect individual behaviour. Jencks and Mayer (1990), for example, distinguish between epidemic (or contagion) models, collective socialisation (or social control) models, and institutional models of neighbourhood effects. "While epidemic models focus on the way in which peers influence one another, collective socialization models focus on the way the adults in a neighborhood influence young people who are not their children. [...] Institutional models also focus on the way adults affect children, but they focus primarily on adults from outside the community who work in $[\ldots]$ neighborhood institutions." (Jencks and 
Mayer 1990, pp.114-115) Along the same lines, Nauck (1995) stresses the role of the 'meso level' as a link between macro-social structures and micro-demographic behaviour. This intermediate level is conceptualised as regional social contexts, which may affect individual behaviour in many different ways, e.g. as opportunity structures, as places of social control and reproduction of cultural patterns, as objects of identification, or as destination of selective migration (Nauck 1995, pp.95-98).

The latter aspect points to the self-selection or 'reflection' problem, i.e. the potential endogeneity of contextual effects (e.g., Evans et al. 1992; Manski 1993). In the presence of selection processes, statistical controls for individual variables would not prevent finding a contextual effect, although it would be hardly possible to identify whether the context is actually influencing the individual's behaviour, or whether the effect is merely a reflection of average characteristics of her environment. In other words, unobserved characteristics of an individual may influence the behaviour under investigation, but also her choice of the environment she lives in. Namely, individuals with a high preference for children should tend to move into regions with opportunity structures that they perceive as being favourable for the formation of a family and the socialisation of children, and vice versa (e.g., Huinink and Wagner 1989). Thus, some proportion of what might be considered as a contextual effect could be an 'indirect' effect only, which is mediated through migration decisions determined by individuals' preferences and the 'push-and-pull' factors of regionally different living conditions. Moreover, selective migration may lead to positive feedback effects on already existing opportunity structures, thereby increasing differences in regional fertility levels.

It is difficult to fully account for all potential challenges to contextual analysis in an empirical investigation. However, an important step towards a sounder basis for 
multilevel research is a better understanding of the 'correspondence' between (regional) social contexts and individual behaviour, i.e. a more detailed knowledge of the mechanisms through which the former exhibit influence on the latter in a historically and socially specific situation. Therefore the relationship between regional opportunity structures as well as local patterns of social interaction and culture on the one hand, and individual fertility decisions on the other hand, will be thoroughly discussed in the remainder of this section.

\subsection{REGIONAL OPPORTUNITY STRUCTURES AND FERTILITY DECISIONS}

One of the main determinants of the living conditions in an individual's environment are local opportunity structures. With regard to fertility decisions, they may be defined mainly by economic opportunities and constraints that are linked to childbearing and its proximate determinants, and the local demography, which affects the costs for engaging in a particular behaviour (see Billy and Moore 1992, p.980). Moreover, Huinink and Wagner (1989, p.676) distinguish between opportunity structures that are relevant for the socialisation of children and such influencing an individual's disposition towards family formation.

The general opportunity structure of an individual's place of residence should be reflected by the degree of urbanisation (cf. Wirth 1938). It has been argued, for example, that urbanisation has created an inappropriate environment for rearing children, particularly regarding housing conditions. Cities moreover provide a social, economic, and cultural infrastructure that offers more alternatives to family formation than rural areas (e.g., Huinink and Wagner 1989). 
More specifically, the local labour market structure should be relevant. An individual woman's propensity to be engaged in market work, for example, is supposed to be positively influenced by a high overall female labour force participation, which is expected to contribute to a greater acceptance of gainful employment as a role model for women (see Brewster and Rindfuss 2000 for a comprehensive overview). It has generally been argued that this would lead to a reduction in fertility, mainly due to the increasing opportunity costs of childrearing in terms of foregone wages and the incompatibility of the mother and worker role. In recent years, however, the negative relationship between fertility and women's employment has apparently reversed in some industrialised countries. This indicates that there are places where women have found ways to combine work and childrearing, while in others they have not (Brewster and Rindfuss 2000, p.279).

The availability of childcare plays a crucial role for this and therefore becomes a central element of a region's opportunity structure (e.g., Kravdal 1996; Kreyenfeld and Hank 2000). Public provision of day care is an important module for establishing an unbroken care arrangement, which is necessary to enable mothers to participate in the labour force. Thus, Stolzenberg and Waite (1984, p.158) argue that "the greater the availability of childcare in a local area, the smaller the constraints of children on the market activity of wives who live there." In western Germany, however, the lack of adequate childcare remains a major institutional barrier to role compatibility (Kreyenfeld and Hank 2000; Hank and Kreyenfeld 2001).

The occupational structure of a region decides upon the availability of qualified jobs. Since employment in the tertiary sector offers career opportunities especially for women (e.g., Blossfeld 1987, p.114), the opportunity costs of motherhood should be 
comparatively high in areas with a prevalence of white-collar jobs, particularly in the absence of sufficient childcare.

The direction of an effect of the regional unemployment rate is less clearly predictable (e.g., De Cooman et al. 1987, p.244). If the unemployment rate is treated as an indicator of the quantity of available jobs within reach, the opportunity costs involved with giving up or reducing market work for starting a family should be high in case of a low unemployment rate. Women's labour market attachment should then be high and fertility should be low, particularly if at the same time a sufficient number of qualified jobs is available. A low unemployment rate, however, may also lead to an increase in a woman's propensity to become a mother (e.g., Hoem 2000, Section 5). The local labour market situation might well be considered as an indicator of a community's socio-economic status and the economic situation in general. If this is perceived as good, a woman (or couple, respectively) might be more likely to regard a child as 'affordable' and therefore decide to have one.

\subsection{Social Interactions, Cultural Milieus, and Individual Fertility}

\section{BEHAVIOUR}

Contextual effects are likely to operate on individuals through social interactions. These take place mainly in intermediate groups which are defined by spatial or social proximity, where the content of an individual's social network is the product of her individual preferences and "associational opportunities and constraints" (Huckfeldt 1983, p.667). Thus, even in the times of mass media and modern means of communication, community norms and direct personal communication remain highly influential when the individual develops her attitudes towards family formation, or 
when it comes to fertility-related processes of social learning (e.g., Montgomery and Casterline 1996).

Regional social contexts may also be viewed as 'culturally normative milieus' (Nauck 1995, p.96), where social control forces individuals to conform to the behavioural expectations of others. Social control presumably works at a small-scale spatial level only and should be facilitated in areas with a homogeneous population, where the individual does not have many possibilities to retreat (e.g., Blalock 1984, p.358). Independent from any kind of social control or direct social influence, an area may finally become a ‘place of identification' (Nauck 1995, p.97), where individuals are assumed to anticipate the adequacy of a certain behaviour in the specific social context they live in. Hammel $(1990$, p.457, 467) calls this "anticipation of [...] cultural evaluation" and develops a notion of culture as "an intensely evaluative cloud of comments", which provides the normative and interpretative rules, according to which individuals consider their fertility decisions.

\section{Empirical Procedure}

\subsection{DATA AND VARIABLES}

\subsubsection{Data sources and selection of the sample}

The individual-level data used in this paper were made available by the German SocioEconomic Panel Study (GSOEP) at the German Institute for Economic Research (DIW Berlin) (see SOEP Group 2001 for a description of the data set). This longitudinal micro-database provides socio-economic information on currently more than 7,000 
households (including an oversample of foreign-headed households) and 14,000 individuals in eastern and western Germany. The survey was started in the western states of Germany and is conducted annually since 1984.

Just recently it has been made possible to link all waves of the GSOEP with detailed information on the respondent's place of residence in any given year of the study period. The 'GSOEP-Geocode' consists of regional indicators provided by the Federal Office for Building and Regional Planning (BBR). They refer to so called $\underline{\text { Raumordnungsregionen, }}$ i.e. functional-spatial units defined by the BBR for the analysis of regional disparities and developments. The data cover such fields as population development, social and economic structure, and the provision of various kinds of infrastructure, which readily allows to approach the role of regional opportunity structures as discussed in Section 2.2. Since the boundaries of the Raumordnungsregionen have been newly defined in 1996, a longitudinal analysis is only possible for periods before or after that year (see BBR 1999). In this paper, information on the 75 western German Raumordnungsregionen for the years 1984 to 1995 is used. $^{1}$

Only respondents from the two original GSOEP subsamples are included in the analysis, i.e. western Germans and foreigners from Greece, Italy, Spain, Turkey, and former Yugoslavia, who already lived in Germany in 1984. Individuals who migrate

\footnotetext{
${ }^{1}$ Individuals may of course be subject to different contextual influences over time. In the present analysis, however, only the individual's current social context is considered, since retrospective data are not available. Thus we assume instantaneous effects that negate possible prior influences. Huinink and Wagner (1989, p.673) label this assumption 'adaptation hypothesis', as opposed to the 'socialisation hypothesis', where an individual's behaviour is assumed to be relatively independent of the living conditions in her contemporary region of residence, but to be influenced mainly by her childhood context.
} 


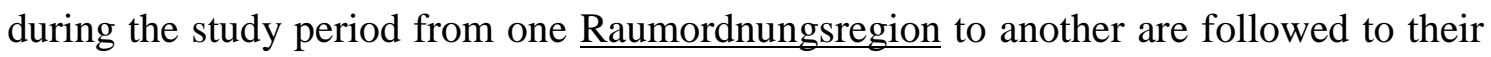
new place of residence. The sample for the analysis of first births consists of 2,474 women, who are observed from age 20 onwards, unless this age was reached before the first year of observation. The upper age limit is 35 years. Since each individual is allowed to contribute multiple observations (see Section 3.2.2), this leads to 10,451 individual records, nested within 75 Raumordnungsregionen. The number of observed first births in the period 1984 to 1995 is 836 . For the analysis of the transition to the second child, information on 1,316 mothers aged 25 to 40 is used. The observation begins after the birth of the first child, or at the beginning of the study period, if the first birth occurred before that. This results in 4,867 individual records and 532 observed second births. Further descriptive sample statistics are displayed in Table 1.

[Table 1 about here]

\subsubsection{Description of the variables}

- Dependent variable

The individual-level binary dependent variable equals 1 in case of the occurrence of a first birth (second birth, respectively) within a one-year interval in the period 1984 to 1995. 
- Individual characteristics (control variables)

Since a non-linear effect of age is assumed, the woman's age and age squared are entered into the regression. For the analysis of second births, the mother's age at first birth (time-constant variable) is considered as well. ${ }^{2}$

Education is treated as a time-varying covariate, measured by a set of binary variables, indicating the respondent's highest educational degree at the time of the survey in each year. It is distinguished between being in education, having no degree, a vocational degree (reference category), or a university degree.

Assuming a close association between a woman's marital status and her propensity to give birth, a time-varying binary variable indicating whether the woman is married at the time of the interview enters the equation.

Finally, to control for possible differences in the fertility behaviour of native Germans and foreigners, a time-constant binary variable is included that indicates whether the respondent belongs to subsample B of the GSOEP (immigrants from Greece, Italy, Spain, Turkey, and former Yugoslavia).

\section{- $\quad \underline{\text { Regional characteristics }}$}

A region's degree of urbanisation is accounted for by a set of three time-constant binary variables. Following the regional typology suggested by the Federal Office for Building and Regional Planning (see BBR 1999, p.2), agglomerations ( $\geq 300$ inhabitants per $\mathrm{km}^{2}$;

\footnotetext{
${ }^{2}$ Models using age categories and the duration since first birth are a common alternative to the specification chosen here. For the analytic purpose of this study, both approaches are equally suitable.
} 
reference category), urbanised areas $\left(\geq 150\right.$ inhabitants per $\left.\mathrm{km}^{2}\right)$, and rural areas $(<150$ inhabitants per $\mathrm{km}^{2}$ ) are distinguished.

The local day-care provision rate is measured by the number of available slots in Kindergarten per 1000 children aged 3 to 6 . This information is taken from the DJI

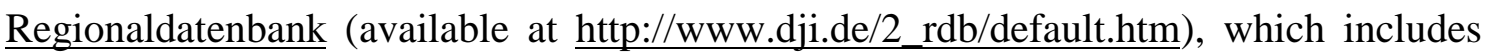
information on the provision of public day-care at the district (Kreis) level. The Kreislevel data are then aggregated to fit the respective Raumordnungsregion. Since regional childcare provision rates are available for the years 1986 and 1994 only, the observation period is divided into two parts, lasting from 1984 to 1989, and from 1990 to 1995 , respectively. While the variable is assumed to be time-constant within each of the two periods, it may change its value between the first and the second half of the observation period.

The local labour market structure is represented here by three time varying variables: the share of employees in the tertiary sector, the regional unemployment rate, and the labour force participation of women. Note that when calculating the female labour force participation rate, only women liable to social security contributions were considered.

\subsection{METHODS}

The data used in this study have two characteristics that require particular attention. First, individuals are nested within regional contexts, hence a multilevel model is in need. Secondly, since the data are observed annually, a discrete-time model is applied. 


\subsubsection{The multilevel model}

Several statistical problems rule out the application of traditional single-level regression models to the analysis of multilevel data (see Hox and Kreft 1994 for a brief overview). Clustering of individuals within the same context results in a hierarchically structured data set and is likely to cause dependency among observations. Ordinarily least squares (OLS) models applied to such data can produce inefficient estimates of the parameters and downwardly biased estimates of their standard errors, because the assumption of independent disturbances - on which OLS is based - is critically violated (see Moulton 1990 for details).

Random coefficient models account for hierarchical data structures. In these models, coefficients may be fixed or random, where the choice between the two alternatives can be made separately for each coefficient in the equation (Hox and Kreft 1994, pp.289-290). In the analysis performed here, all regression coefficients other than the intercept are constrained to be fixed across the regional units, i.e. we assume that the effect of the explanatory variables does not differ between contexts. The equation for this 'random intercept model' is

$$
\mathrm{y}_{\mathrm{ij}}=\underline{\mathrm{b}}_{0}+\underline{\mathrm{b}}_{1} \underline{\mathrm{x}}_{\mathrm{ij}}+\mathrm{b}_{2} \underline{\mathrm{V}}_{\mathrm{j}}+\mathrm{u}_{0 \mathrm{j}}+\varepsilon_{\mathrm{ij}}
$$

where $y_{i j}$ represents the outcome of the dependent variable $y$ for individual $\underline{i}$ within context $\mathrm{j}, \underline{\mathrm{x}}_{\mathrm{ij}}$ is the individual-level explanatory variable, and $\underline{\mathrm{v}}_{\mathrm{j}}$ the macro-level explanatory variable. The random intercept's fixed component $\underline{b}_{0}$ and the slopes $\underline{b}_{1}$ and $\underline{\mathrm{b}}_{2}$ are the parameters of the equation. The error term is more complex than in traditional regression equations, since it includes not only the micro error $\underline{\varepsilon}_{\mathrm{ij}}$, but also the macro error $\underline{\mathrm{u}}_{0 j}$. The latter indicates that the intercept may vary over contexts, i.e. $\underline{\mathrm{u}}_{0 \mathrm{j}}$ measures 
the deviation of each context from $\underline{b}_{0}$ (between-context variance). It captures otherwise unobserved regional effects and accounts for the correlation between individuals nested within the same context. All $\underline{\varepsilon}_{\mathrm{ij}}$ are assumed to be independent of each other with the expectation zero and the variance $\sigma_{\varepsilon}^{2}$. The macro-level disturbances $\underline{\mathrm{u}}_{0 \mathrm{j}}$ are independent of the individual-level disturbances, have the expectation zero and the variance $\sigma_{u}^{2}$. If the $\underline{\mathrm{u}}_{0 \mathrm{j}}$ turn out to be statistically significant from zero, context effects are present (e.g., Kreft and de Leeuw 1998, Chapter 3.4).

Multilevel generalised linear models (GLIM) can be used to overcome some of the shortcomings of simple random coefficient models, such as the underlying assumption of a normal error distribution. Hierarchical GLIM therefore allow the application of multilevel logistic regression models for the analysis of discrete dependent variables (see Guo and Zhao 2000 for an overview). The two-level model for a binary response variable is conceptually equivalent to equation [1]. The probability of the binary outcome to be one is defined as $\mathrm{p}_{\mathrm{ij}}=\operatorname{Pr}\left(\mathrm{y}_{\mathrm{ij}}=1\right)$, where $\mathrm{p}_{\mathrm{ij}}$ is modelled using a logit link function. With the standard assumption that $\mathrm{y}_{\mathrm{ij}}$ has a Bernoulli distribution, the multilevel logistic model can be written as

$$
\left.\underline{\log \left[p_{\mathrm{ij}}\right.} /\left(1-\mathrm{p}_{\mathrm{ij}}\right)\right]=\underline{\mathrm{b}}_{0}+\underline{\mathrm{b}}_{1} \underline{\mathrm{x}}_{\mathrm{ij}}+\mathrm{b}_{\underline{2}} \underline{\mathrm{v}}_{\mathrm{j}}+\mathrm{u}_{0 \mathrm{j}}
$$

where the same assumptions as in the case of multilevel linear models apply to $\underline{\mathrm{u}}_{0 \mathrm{j}}$, i.e. the random effect is assumed to be normally distributed, with the expected value 0 and the variance $\sigma_{u}^{2}$. 


\subsubsection{The discrete-time logit model}

Most methods developed for the analysis of event histories require that time is measured as a continuous variable. In this study, however, annual information on the respondent and her place of residence is used. Since these data cannot be treated as if they were continuous, a discrete-time model is applied here (e.g., Allison 1982; Yamaguchi 1991). A common choice to specify how the discrete-time hazard rate is determined, is the logistic regression function (Allison 1982, p.72). If the conditional probabilities that an event occurs at time $\underline{t}$, given that it has not already occurred, are sufficiently small (i.e. not larger than 0.1 , the logit model provides a good approximation to the continuous time proportional hazards model (Yamaguchi 1991, p.18, 42).

The discrete-time logit model estimates the effect of a number of covariates on the $\log$ of the odds of an event. In the present case, the log odds that a woman experiences a first birth (second birth, respectively) within the one-year interval t is

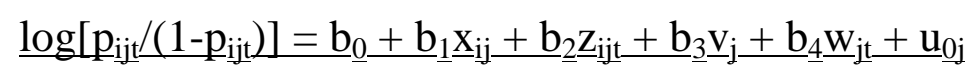

where $\mathrm{p}_{\mathrm{ijt}}$ is the probability of individual $\underline{\mathrm{i}}$ in region $\mathrm{j}$ to have a birth of a specific order in year $\underline{\mathrm{t}}, \underline{\mathrm{b}}_{0}$ is the intercept constrained to be equal across all years, $\underline{\mathrm{x}}_{\mathrm{ij}}$ and $\underline{\mathrm{v}}_{\mathrm{j}}$ are vectors of time-constant explanatory variables, $\underline{\mathrm{z}}_{\mathrm{ijt}}$ and $\underline{\mathrm{w}}_{\mathrm{jt}}$ are vectors of time-varying explanatory variables at time $\underline{\mathrm{t}}$, and $\underline{\underline{u}}_{0 \mathrm{j}}$ is the regional-level random effect.

Different from conventional logistic regression analysis, discrete-time logit models use multiple observations for each individual in the sample, i.e. each time unit during which an individual is observed contributes a separate and independent observation to the input data (Allison 1982, pp.81-87). Since a birth of a specific order is a non-repeatable event, the individual is excluded from any further observation, once the event has occurred. This leads to insufficient variation in the dependent variable, 
prohibiting identification of an individual-level unobserved heterogeneity component, as would be the case in a normal panel regression model. For a detailed discussion of discrete-time multilevel hazard models see Barber et al. (2000).

\section{Regression Results}

The results of the multivariate analysis will be presented separately for first and second births. For the estimation, a strategy of stepwise inclusion of variables is applied. To begin with, a regression with just the intercept and the regional random effect is run (Model 1). In Models 2 to 4, the individual-level variables are introduced. Finally, the regional-level variables are added in Models 5 and 6.

For the analysis the software package aML is used (see Lillard and Panis 2000).

\subsection{ANALYSIS OF FIRST BIRTHS}

In all models, the coefficients of the individual-level control variables show the anticipated signs and are usually statistically significant where expected. Compared to women with a vocational degree, being in education strongly reduces the propensity to have a first birth. This is consistent with other studies, which also find that "women postpone childbearing until after they complete the desired amount of education." (Rindfuss et al. 1996, p.279) Having a university degree, on the other hand, does not have any statistically significant impact. The positive coefficient of the dummy variable indicating that the woman terminated education without receiving any vocational or university degree looses its significance, once it is controlled for the woman's marital status (Models 4 to 6 ). Including the marital status in the analysis clearly reduces the 
original size of most other individual-level coefficients and leads to a substantial improvement in the model's fit. As expected, the risk of married western German women to experience a first birth is many times higher than for the unmarried. ${ }^{3}$

Adding regional components to the regression does not increase its explanatory power. Although the standard deviation of the regional random effect $\left(\sigma_{\mathrm{u}}\right)$ in $\underline{\text { Model } 2}$, and the coefficient of the female labour force participation (FLPR) variable in $\underline{\text { Model } 6}$ turn out to be statistically significant at the ten per cent level, they cannot be interpreted in a substantively meaningful manner. Apart from these two exceptions, neither the regional random effect, nor any of the other regional indicators exhibits a statistically significant effect on the woman's risk of having a first child. It is interesting to note, though, that the size of $\sigma_{\mathrm{u}}$ basically remains the same in Models 1 to 3 , but decreases to almost zero, as soon as the woman's marital status is taken into account.

[Table 2 about here]

\subsection{ANALYSIS OF SECOND BIRTHS}

Just as in the analysis of first births, the age function for the transition to the second child exhibits a concave shape. In all models, a woman's age at first birth is significantly correlated with her probability of having a second child. The positive sign of the coefficient is as expected, since a higher age at entry into parenthood allows less postponement of another birth. The same line of reasoning holds for the interpretation of

\footnotetext{
${ }^{3}$ Of course we are aware of the fact that endogeneity is an issue here. However, in this paper our primary concern is not the causal relationship between the individual-level variables, but the role of the contextual variables, i.e. the former 'merely' serve as control variables.
} 
the educational variables (Models 3 to 6). Women who received a university degree are found to have a higher propensity to progress to parity two in the study period than women in the reference category, which is likely to be a 'catching-up' effect. Blossfeld and Huinink (1991, pp.164-165), for example, argue that "because attainment of increasing levels of education takes time and is connected with women's increasing age $[\ldots]$ highly qualified women $[\ldots]$ come increasingly under pressure", if they want to realise their fertility goals. The coefficient of the dummy variable for being in education is - although large - not statistically significant, which is due to the small number of women in the sample who are in education still (one per cent). Finally, being married strongly increases a woman's propensity to have a second birth, although the effect is somewhat smaller than for the transition to the first child.

In $\underline{\text { Model } 1}$, the standard deviation of the regional random effect $\left(\sigma_{\mathrm{u}}\right)$ turns out to be statistically significant, which indicates that the intercept varies over contexts. The context effect looses its significance, though, as soon as individual-level control variables are entered into the regression. The size of the coefficient is reduced by about forty per cent, even if only the individual's age, age squared, and her age at first birth are controlled for. Adding indicators of a region's degree of urbanisation (Model 5) does not lead to a statistically significant improvement of the model's fit. Living in a rural area, though, has a weakly significant effect on the woman's risk to progress to parity two, and the positive sign of the coefficient is consistent with the theoretical expectations discussed above. However, the specific impact of urbanity is partly absorbed by the influence of the other regional indicators (Model 6). Controlling for these variables also reduces $\sigma_{\mathrm{u}}$ to zero, although they themselves do not yield any 
statistically significant effect on a woman's fertility outcome during the observation period.

[Table 3 about here]

\section{Conclusions and Perspectives for Future Research}

In the theoretical part of this paper it has been discussed how regional opportunity structures as well as local patterns of social interaction and culture may translate into parameters that directly affect individual childbearing behaviour. However, the empirical analysis performed here provides no evidence that the distinct fertility differences observed in western Germany at the regional level (cf. Hank 2001a) are due to autonomous contextual effects. The regression results rather suggest that most of the regional variation may result from differences in the spatial distribution of individual characteristics (see also Kopp 2000). This holds particularly for the occurrence of first births during the observation period. The analysis of the transition to the second child, however, reveals at least some (weak) 'footprints' of an effect of the regional social context. This is consistent with the finding that regional fertility differences in post-war West Germany have been evident especially for higher parity births (Birg et al. 1990).

Our empirical results should clearly not discourage further research into the relationship between regional social contexts and individual fertility decisions. First, it will be necessary to investigate the influence of the choice of a specific regional context on the empirical outcome of the analysis, since the correct specification of the context is naturally a crucial matter. Secondly, since giving birth is only the final outcome of a 
number of previous fertility-related decisions and events, it is desirable to examine contextual influences on such events as union formation or first sexual intercourse (e.g., Billari and Borgoni 2001). ${ }^{4}$ For this purpose, one should - thirdly - make an effort to better utilise and exploit regionalised survey data (see Hoffmeyer-Zlotnik 2000 for a discussion) as well as other large-scale individual-level data sources, such as census or register data (e.g., Hoem 2000). Fourth, and last, researchers might want to transcend the standard geographical focus of social contextualisation and aim at gathering more qualitative data. Hammel (1990, p.467), for example, argues that a "successful incorporation of anthropological concepts of culture into demographic explanation" requires careful ethnography that allows "comparative studies of relatively small social units, however large and complex may be the societies within which these are embedded."

\footnotetext{
${ }^{4}$ A first analysis of the process of family formation using the GSOEP and district (i.e. $\underline{\text { Kreis) }}$ level data suggests that (1) a more local definition of the social context does not change the results presented here as regards women's entry into motherhood, but that (2) there is a persistent regional effect on women's risk of entering first marriage, which might be attributed to local nuptiality customs (Hank 2001b).
} 


\section{References}

Allison, P.A. 1982. 'Discrete-Time Methods for the Analysis of Event Histories', in S. Leinhardt (ed.), Sociological Methodology 12. San Francisco: Jossey-Bass, 61-98.

Axinn, W.G., S.T. Yabiku. 2001. 'Social Change, the Social Organization of Families, and Fertility Limitation', American Journal of Sociology 106: 12191261.

Barber, J.S., S.A. Murphy, W.G. Axinn, and J. Marples. 2000. 'Discrete-time multilevel hazard analysis', in M.E. Sobel and M.P. Becker (eds.), $\underline{\text { Sociological }}$ Methodology 30. Washington: Blackwell Publishers, 201-235.

Billari, F.C., and R. Borgoni. 2001. 'Spatial Profiles in the Analysis of Event Histories: An Application to First Sexual Intercourse in Italy', MPIDR Working Paper WP 2001-025, available http://www.demogr.mpg.de/Papers/Working/wp-2001-025.pdf.

Billy, J.O., and D.E. Moore. 1992. 'A multilevel analysis of marital and nonmarital fertility in the U.S.', Social Forces 70: 977-1011.

Birg, H., D. Filip, and E.-J. Flöthmann. 1990. 'Paritätsspezifische Kohortenanalyse des generativen Verhaltens in der Bundesrepublik Deutschland nach dem 2. Weltkrieg', IBS-Materialien, No.30, Bielefeld.

Blalock, H.M. 1984. 'Contextual-Effects Models: Theoretical and Methodological Issues', Annual Review of Sociology 10: 353-372.

Blossfeld, H.-P. 1987. 'Labor-Market Entry and the Sexual Segregation of Careers in the Federal Republic of Germany', American Journal of Sociology 93: 89118.

Blossfeld, H.-P., and J. Huinink. 1991. 'Human Capital Investments or Norms of Role Transition? How Women's Schooling and Career Affect the Process of 
Family Formation', American Journal of Sociology 97: 143-168.

Brewster, K.L., and R.R. Rindfuss. 2000. 'Fertility and Women's Employment in Industrialized Nations', Annual Review of Sociology 26: 271-296.

Brunetta, G., and G. Rotondi. 1991. 'Urban and rural fertility in Italy: Regional and temporal changes', in J. Bähr and P. Gans (eds.), The Geographical Approach to Fertility, Kieler Geographische Schriften, Vol. 78. Kiel: Geogr. Inst. d. Univ. Kiel, 203-218.

Bundesamt für Bauwesen und Raumordnung (BBR). 1999. Aktuelle Daten zur Entwicklung der Städte, Kreise und Gemeinden, Reports Vol. 3. Bonn: BBR.

Burton, L.M., and R.L. Jarrett. 2000. 'In the Mix, Yet on the Margins: The Place of Families in Urban Neighborhood and Child Development Research', Journal of Marriage and the Family 62: 1114-1135.

Coale, A.J., and S.C. Watkins (Eds.). 1986. The Decline of Fertility in Europe. Princeton: Princeton University Press.

Conrad, C., M. Lechner, and W. Werner. 1996. 'East German Fertility After Unification: Crisis or Adaptation?', Population and Development Review 22: 331-358.

Courgeau, D., and B. Baccaini. 1998. 'Multilevel Analysis in the Social Sciences', Population (English Selection) 10: 39-71.

De Cooman, E., J. Ermisch, and H. Joshi. 1987. 'The next birth and the labour market. A dynamic model of births in England and Wales', Population Studies 41: 237-268.

DiPrete, T.A., and J.D. Forristal. 1994. 'Multilevel Models - Methods and Substance', Annual Review of Sociology 20: 331-357.

Entwisle, B., J.B. Casterline, and H.A.-A. Sayed. 1989. 'Villages as Contexts for Contraceptive Behavior in Rural Egypt', American Sociological Review 54: 1019-1034. 
Erbring, L., and A.A. Young. 1979. 'Individuals and Social Structure. Contextual Effects as Endogenous Feedback', Sociological Methods \& Research 7: 396430.

Evans, W.N., W.E. Oates, and R.M. Schwab. 1992. 'Measuring Peer Group Effects: A Study of Teenage Behavior', Journal of Political Economy 100: 966-991.

Ginther, D., R. Haveman, and B. Wolfe 2000. 'Neighborhood Attributes as Determinants of Children's Outcomes', Journal of Human Resources 35: 603642.

Gonzalvez Perez, V. 1989. 'Crise et contrastes spatiaux de la fécondité espagnole', Espace, Populations, Sociétes No.2: 201-213.

Guo, G., and H. Zhao. 2000. 'Multilevel Modeling for Binary Data', Annual Review of Sociology 26: 441-462.

Hammel, E.A. 1990. 'A Theory of Culture for Demography', $\underline{\text { Population and }}$ Development Review 16: 455-485.

Hank, K. 2001a. 'Regional Fertility Differences in Western Germany. An Overview of the Literature and Recent Descriptive Findings', International Journal of Population Geography 7: 243-257.

Hank, K. 2001b. 'The Differential Influence of Women's Residential District on Their Risk of Entering Motherhood and First Marriage. A Discrete-Time Multilevel Analysis of Western German Panel Data, 1984-1999.' Mimeo, MPIDR, Rostock.

Hank, K., and M. Kreyenfeld. 2001. 'Childcare and Fertility in (Western) Germany', MPIDR Working Paper WP 2001-019, available http://www.demogr.mpg.de/Papers/Working/wp-2001-019.pdf.

Hauser, R.M. 1974. 'Contextual Analysis Revisited', Sociological Methods \& Research 2: 365-375.

Hirschman, C., and P. Guest. 1990. 'Multilevel Models of Fertility Determination in 
Four Southeast Asian Countries: 1970 and 1980', Demography 27: 369-396.

Hoem, B. 2000. 'Entry into motherhood in Sweden: the influence of economic factors on the rise and fall in fertility, 1986-1997', Demographic Research [Online] 2, available http://www.demographic-research.org/Volumes/Vol2/4.

Hoffmeyer-Zlotnik, J.H.P. 2000. Regionalisierung sozialwissenschaftlicher Umfragedaten. Opladen: Westdeutscher Verlag.

Höpflinger, F. 1983. 'Regionale Unterschiede der Geburtenhäufigkeit in der Schweiz', in Akademie für Raumforschung und Landesplanung (ed.), Regionale Aspekte der Bevölkerungsentwicklung unter den Bedingungen des Geburtenrückgangs, Forschungs- und Sitzungsberichte, Vol. 144. Hannover: Vincentz, 67-80.

Hox, J.J., and I.G.G. Kreft. 1994. 'Multilevel Analysis Models', Sociological Methods \& Research 22: 283-299.

Huber, J. (ed.). 1991. Macro-Micro Linkages in Sociology. Newbury Park: Sage.

Huckfeldt, R.R. 1983. 'Social Contexts, Social Networks, and Urban Neighborhoods: Environmental Constraints on Friendship Choice', American Journal of Sociology 89: 651-669.

Huinink, J., and M. Wagner. 1989. 'Regionale Lebensbedingungen, Migration und Familienbildung', Kölner Zeitschrift für Soziologie und Sozialpsychologie 41: 669-689.

Jencks, C., and S.E. Mayer 1990. 'The Social Consequences of Growing Up in a Poor Neighborhood', in L.E. Lynn and M.G.H. McGeary (eds.), Inner-City Poverty in the United States. Washington: National Academy Press, 111-186.

Kopp, J. 2000. 'Geburtenentwicklung in Ost- und Westdeutschland', in H. Bertram et al. (eds.), Solidarität, Lebensformen und regionale Entwicklung. Opladen: Leske+Budrich, 83-135.

Kravdal, Ø. 1996. 'How the local supply of day-care centers influences fertility in 
Norway: A parity-specific approach', Population Research and Policy Review 15: $201-218$

Kreft, I., and J. de Leeuw. 1998. Introducing Multilevel Modeling. London: Sage.

Kreyenfeld, M., and K. Hank. 2000. 'Does the availability of child care influence the employment of mothers? Findings from western Germany', Population Research and Policy Review 19: 317-337.

Kutzenberger, K., and E. Fürst. 1983. 'Die regionalen Unterschiede der Geburtenhäufigkeit in Oberösterreich (1969-1978)', in Akademie für Raumforschung und Landesplanung (ed.), Regionale Aspekte der Bevölkerungsentwicklung unter den Bedingungen des Geburtenrückgangs, Forschungs- und Sitzungsberichte, Vol. 144. Hannover: Vincentz, 51-66.

Lesthaeghe, R. 1995. 'The second demographic transition in Western countries: an interpretation', in K.O. Mason and A.-M. Jensen (eds.), Gender and family change in industrialized countries. Oxford: Clarendon Press, 17-62.

Lillard, L.A., and C.W.A. Panis. 2000. aML Multilevel Multiprocess Statistical

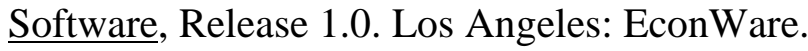

Manski, C.F. 1993. 'Identification of Endogenous Social Effects: The Reflection Problem', Review of Economic Studies 60: 531-542.

Montgomery, M.R., and J.B. Casterline. 1996. 'Social Learning, Social Influence, and New Models of Fertility', in: J.B. Casterline et al. (eds.), Fertility in the United States: New Patterns, New Theories, Supplement to Population and Development Review 22: 151-75.

Moulton, B.R. 1990. 'An Illustration of a Pitfall in Estimating the Effects of Aggregate Variables on Micro Units', The Review of Economics and Statistics 32: 334-338.

Nauck, B. 1995. 'Regionale Millieus von Familien in Deutschland nach der politischen Vereinigung', in B. Nauck and C. Onnen-Isemann (eds.), Familie 
im Brennpunkt. Neuwied: Luchterhand, 91-121.

Noin, D., and Y. Chauviré 1991. 'The geographical disparities of fertility in France', in J. Bähr and P. Gans (eds.), The Geographical Approach to Fertility, Kieler Geographische Schriften, Vol. 78. Kiel: Geogr. Inst. d. Univ. Kiel, 151164.

Rindfuss, R.R., S.P. Morgan, and K. Offutt. 1996. 'Education and the Changing Pattern of American Fertility: 1963-1989', Demography 33: 277-290.

Snijders, T.A.B., and R.J. Bosker. 1999. Multilevel analysis: An introduction to basic and advanced multilevel modeling. London: Sage.

SOEP Group. 2001. 'The German Socio-Economic Panel (GSOEP) after more than 15 years - Overview', in E. Holst et al. (eds.), Proceedings of the 2000 Fourth International Conference of German Socio-Economic Panel Study Users (GSOEP 2000), Vierteljahrshefte zur Wirtschaftsforschung 70: 7-14.

Stolzenberg, R.M., and L.J. Waite. 1984. 'Local Labor Markets, Children and Labor Force Participation of Wives', Demography 21: 157-170.

Wirth, L. 1938. 'Urbanism as a Way of Life', American Journal of Sociology 44: 124.

Yamaguchi, K. 1991. Event History Analysis. Newbury Park: Sage. 


\section{Tables}

Table 1: Descriptive sample statistics - first and second births, 1984 to 1995

\begin{tabular}{|c|c|c|}
\hline & $\begin{array}{c}\text { First birth } \\
\text { Mean }(\operatorname{Stdv} .)^{a)}\end{array}$ & $\begin{array}{l}\text { Second birth } \\
\text { Mean }(\operatorname{Stdv} .)^{a)}\end{array}$ \\
\hline Number of births & 836 & 532 \\
\hline \multicolumn{3}{|l|}{ Individual level } \\
\hline Age & $25.1(4.0)$ & $31.8(4.4)$ \\
\hline Age squared & $648.5(212.2)$ & $1030.9(287.4)$ \\
\hline Age at first birth & - & $25.0(4.1)$ \\
\hline In education & 0.17 & 0.01 \\
\hline No degree & 0.18 & 0.24 \\
\hline Vocational degree & 0.57 & 0.68 \\
\hline University degree & 0.07 & 0.06 \\
\hline Marital status & 0.28 & 0.82 \\
\hline Foreigner & 0.23 & 0.24 \\
\hline \multicolumn{3}{|l|}{ Regional level $^{\text {b) }}$} \\
\hline Agglomeration & 0.62 & 0.62 \\
\hline Urbanised area & 0.26 & 0.26 \\
\hline Rural area & 0.12 & 0.12 \\
\hline $\begin{array}{l}\text { Day-care provision (\# of slots per } \\
1000 \text { children aged } 3 \text { to } 6 \text { ) }\end{array}$ & $829.2(162.0)$ & $831.8(164.1)$ \\
\hline Tertiary sector (in per cent) & $52.5(8.4)$ & $52.1(8.7)$ \\
\hline Unemployment rate (in per cent) & $8.1(3.0)$ & $8.1(3.0)$ \\
\hline $\begin{array}{l}\text { Female labour force participation } \\
\text { rate (FLPR) (in per cent) }\end{array}$ & $42.1(6.5)$ & $42.1(6.6)$ \\
\hline $\mathrm{N}$ (regions) & 75 & 75 \\
\hline $\mathrm{N}$ (women) & 2,474 & 1,316 \\
\hline $\mathrm{N}$ (spells) & 10,451 & 4,867 \\
\hline \multicolumn{3}{|c|}{$\begin{array}{l}\text { Note: } \\
\text { a) Standard deviations are not displayed for binary variables. } \\
\text { b) Minor differences in the mean values of some of the regional-level variables for first } \\
\text { and second births are due to a slightly different distribution of the individuals across } \\
\text { Raumordnungsregionen. }\end{array}$} \\
\hline
\end{tabular}

Source: GSOEP and GSOEP-Geocode 1984-1995, author's calculations 


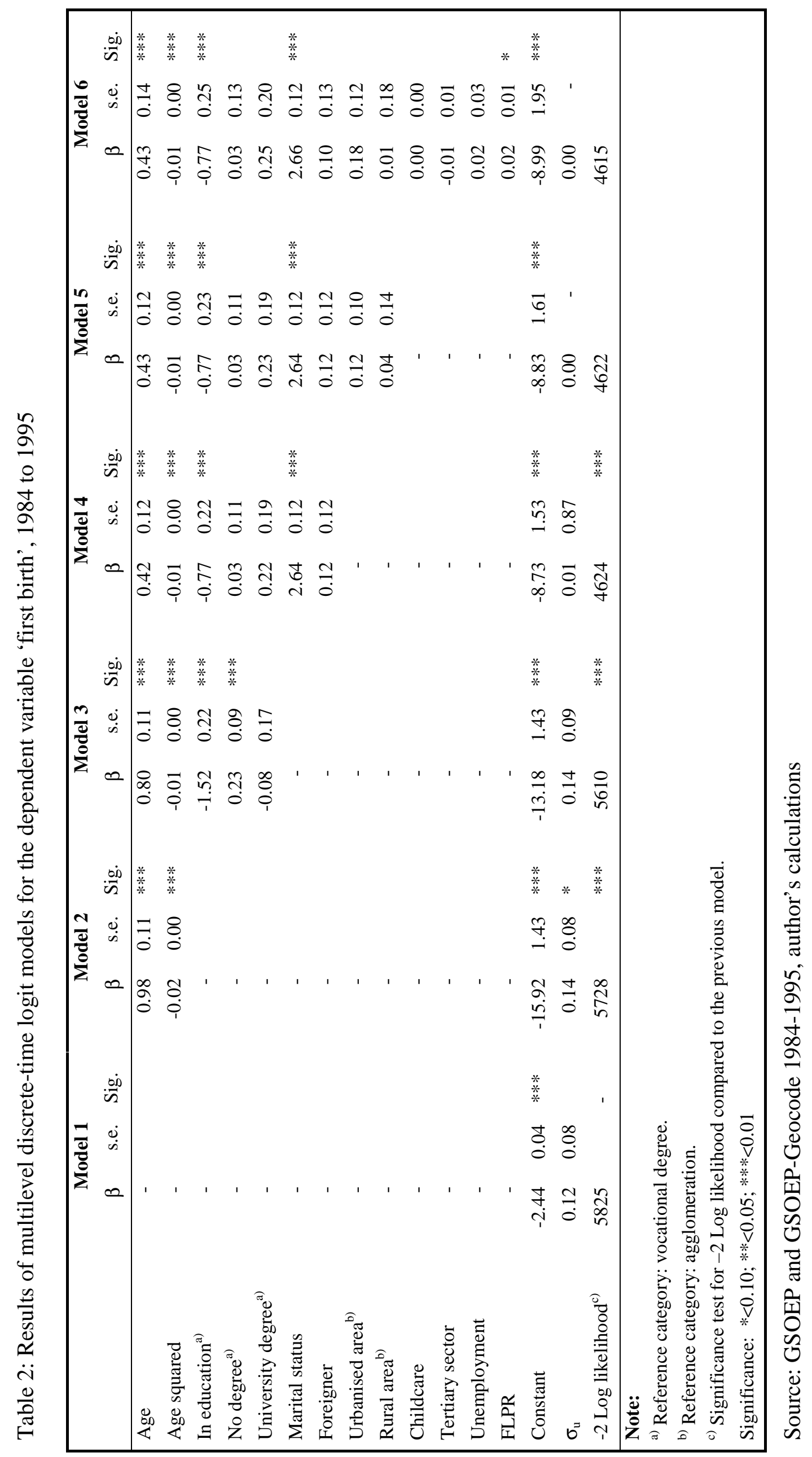




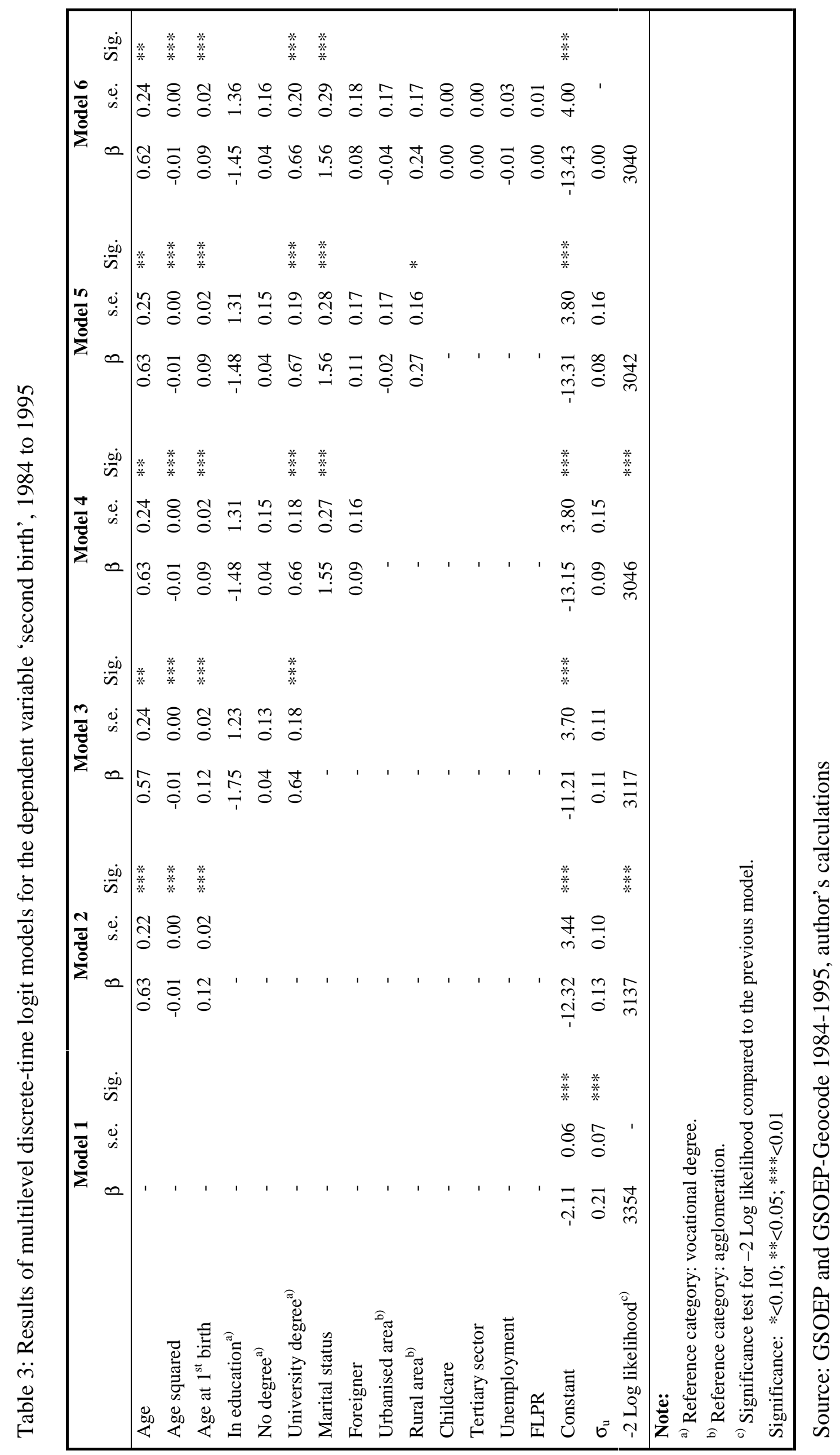

